\title{
SELECTION OF SUPPLIER IN B2B E-COMMERCE USING WORK FLOW PETRI NET
}

\author{
Samara Mubeen ${ }^{1}$ and K.N.Subramanya ${ }^{2}$ \\ ${ }^{1}$ Department of Information Science and Engineering, J.N.N.College of engineering, \\ Shimoga, Karnataka, India \\ ${ }^{2}$ Department of IEM, R.V. College of engineering, Bangalore, Karnataka, India.
}

\begin{abstract}
The internet has become the prime driver of contemporary E-commerce. E-procurement is important aspect of e-commerce where exchange of the information about the order is done. Data Interchange to the internet, the focus is still on the technology required to exchange information rather than supporting process crossing organizational borders. Selection of the supplier is the most important aspect of both the traditional EDI and B2B E-commerce. In this paper we design an workflow model of e-procurement for selection of the supplier is done by considering the traditional aspects of performance quality and performance analysis tool work flow ne a concept of Petri net.
\end{abstract}

\section{KEYWORDS}

Selection supplier, business-to-business, e-procurement model, workflow net, Petri net.

\section{INTRODUCTION}

The B2B e-commerce is becoming an increasingly important method of conducting buying and selling processes. Although discussion and analysis revolves around the experience and lessons from the B2B marketplaces and exchanges, the work has much broader application, and in particular to the e-sourcing initiatives of large companies which include supplier extranets and private exchanges. The internet has given way for supplying of enterprises from smallest enterprises to largest corporations to establish global presence. The supplying enterprise has the opportunity to reach geographically dispersed markets that would be cost prohibitive to consider. E-procuring have the opportunity to select the best suppliers, by the best supplier is the one who can supply the sub product at less delivery time and the throughput. Hence the choice of suppliers plays an important role in reducing the wastage.

The increasingly competitive global world markets put industries under intense pressure to find ways to cut material costs to survive and sustain their competitive position in their respective markets. Since a qualified supplier is a key element and a good resource for a buyer in reducing.

The paper is dividing into following section 2 theoretical backgrounds, section 3e-procurement entities and workflow model, section 4 Performance analyses of work flow net, section 5 Test cases and result analysis and section 6 conclusions.

\section{Theoretical Background:}

a review of literature is made for different techniques used for section of the supplier and some of the drawbacks at stated. 
Luitzenet.al A review of methods supporting supplier selection. The review range from four main points what is achieved by the selection of supplier, defining the criteria, prequalifying suitable supplies to and making final decisions. In this paper more importance is given to supplier characteristics for e.g. its process employees, culture etc. rather than merely the specific products or services they provide.

Keith Goffin et.al An Exploratory study of close supplier manufacturer relationships. it highlights the closeness between the supplier and manufacturer which is important for reliable delivery of quality, well priced parts and components. This paper does not have methodology and frame work.

W.M.R. Van Der Aalst Process oriented architecture for electronic commerce and inter organizational workflow. This paper stresses the process aspects of E-commerce by relating it to workflow management. Traditional workflow management system assumes one centralized enactment service and have problem during dynamic changes and local variation. The dynamics of the market place with rapid changing business processes and relationship, underline the need for verification tools Petri net is used to model workflow. But the framework for B2B does not show the parameter consider for verifying the selection of the supplier.

S.HossienCheraghi et.al Critical success factors for selection for supplier selection: An update, selection of the supplier is done from the work of Dickson, they conclude that supplier criteria will continue to change based on an expanded definition of traditional aspects of performance and evolving ones and nontraditional aspects. They have consider only delivery, price service as traditional aspects.

LusanEvaluation on suppliers selection in the context of e-commerce based on trapezoidal fuzzy weighted average operator, main focus of selctio0n of supplier is considered using fuzzy order weighted average operators are used for evaluation. Here it is necessary to constantly enrich and improve the index system of supplier selection in light of companies own situation.

Alderate Maria VeronicaE-commerce between a large firm and a SME supplier: a screening model, this paper derives a model of screening contracts in the presence of positive network effects when building an electronic commerce network between a large firm and small and medium sized enterprise supplier based on Compete. Compete is main insight when several potential candidates compete for the task. Depending on the some performance parameters the supplier are selected.

\section{Theoretical Background.}

E-procurement entities and workflow model. The sourcing model is the important part of the $\mathrm{B} 2 \mathrm{~B}$ e-commerce. The manufacturer is going assemble the parts which we call as sub product send by different supplier into main product. The sending of the order and processing the request and sending the time when the sub product will reach the manufacturer is estimated. The Eprocurement model consist of the following entitles

- Procurement: this one of the important entity of $b 2 b$ sourcing model which shows of getting the product from the suppliers. The procurement entities consist of procurement of material and service. This is judged depending upon the delivery time of the product, the delivery time is waiting time and throughput. This is done for one supplier and nsuppliers. Among n-suppliers only efficient suppliers are selected.

- Manufacturer order for product: the manufacture order the product here we consider product $\mathrm{b}$ and product $\mathrm{c}$ are manufactured by suppliers and assembled to form the product a, which carried out at the manufacturer. Manufacturer order for the product randomly. 
- Manufacturer requirement is to get the products from the suppliers to be assembled to final product. Here product $\mathrm{b}$ and product $\mathrm{c}$ are assembled to final product $\mathrm{a}$ in the example.

- Market demand is the demand for the product in the market for e.g. chips from semiconductor manufacturing industry or product in the automobile industry.

\subsection{The workflow model of the e-procurement}

The e-procurement model of $\mathrm{b} 2 \mathrm{~b}$ is shown in the figure 1 , which starts from the market demand to user requirement to manufacturer order for the product. Manufacturer order for the product goes to the procurement process which consists of request for the material and procurement of service.

Procurement process is divided into two process generic model which should have exactly two suppliers and n-supplier's process whose performance is obtained from the order of the product, the time required for information to reach the supplier for supplying of the products is the move time, process time required to process the request, queue time the time required to for the request to wait in the queue, inspection time is to inspect the request is correct or not from authorized manufacturer to authorized supplier. Finally we get the delivered time of the product to the manufacturer from which the selection of the suppliers is done.

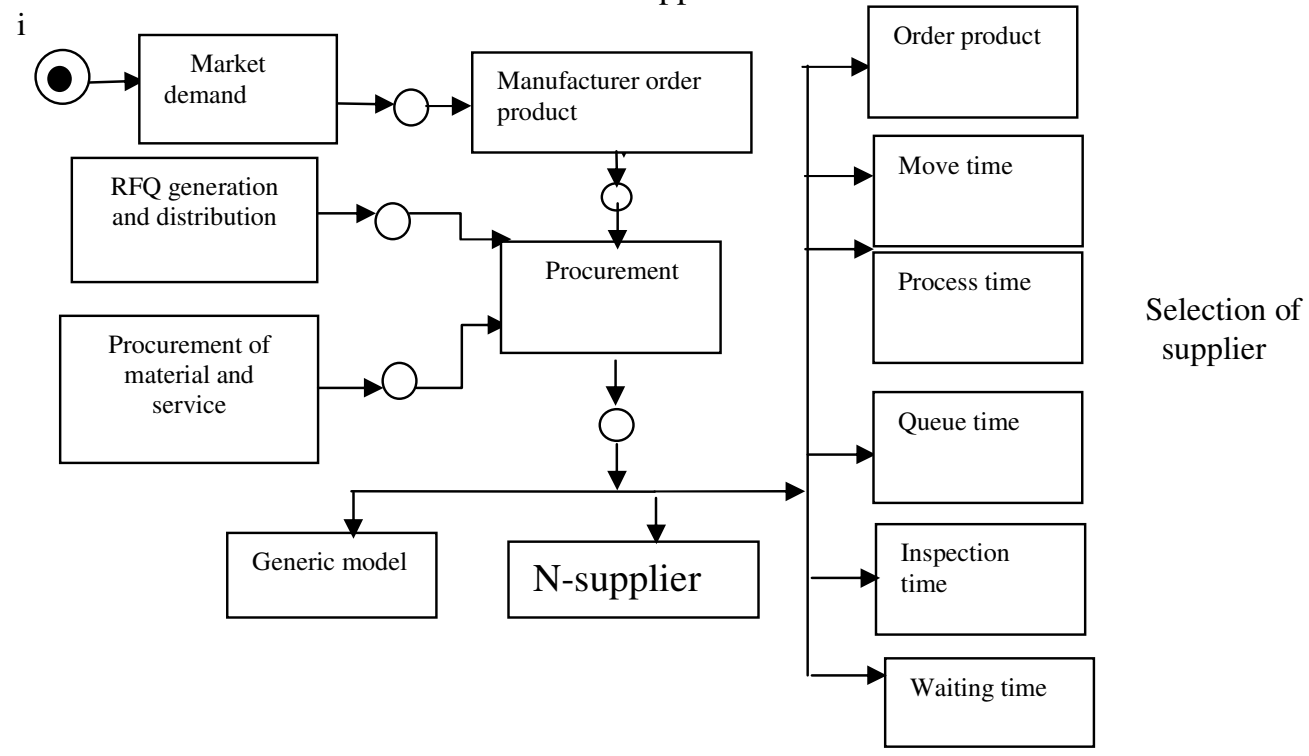

Figure 1. Workflow model of e-procurement in B2B.

\subsection{E-procurement model using work flow net}

The Petri net which models the process aspects of a workflow is called a Work flow net, it specifies the dynamic behaviour of a single case in isolation. The work flow diagram is given in the figure 2.The manufacturer sent the order for the sub product the suppliers are randomly selected from the list of available suppliers. Sometimes since the suppliers are randomly selected same supplier may selected in the same session of manufacturing for the product. Only few suppliers may be selected from the available list of the suppliers and sometimes all suppliers are selected from the available suppliers.

The diagram shows the work flow net of generic model having manufacturer, supplier1 and supplier2. The manufacturer wants to manufacture product a for manufacturing it he requires two sub product i.e. sub product and sub product $\mathrm{c}$ respectively which supplier 1 and supplier 2 
manufactures. The Work flow net shows the RO_a which means it receives the order for the product $\mathrm{a}$, send order for manufacturing of sub product $\mathrm{b}$ and sub product $\mathrm{c}$ to the two suppliers by $\mathrm{SO}_{-} \mathrm{b}$ to supplier1 and $\mathrm{SO}_{-} \mathrm{c}$ to supplier2, this called move time after sending the order the manufacturer waits for the arrival of sub product information which is given in the workflow Petri net as WT_bc. After receiving RO_b and RO_c from manufacturer, time required to process is found out called process time which is represented as PT_b and PT_c for both supplier, the confirmation whether correct process time is generated or NK_b and Nk_c not is checked called the inspection time IT, if not again the order is feedback. If everything is ok then sub product is send for assembling at manufacturer. At manufacturer after assemble of main product done and throughput and delivery time is calculated. The throughput is given by summation of move time, process time and inspection time. The delivery time is given by summation of throughput and waiting time.

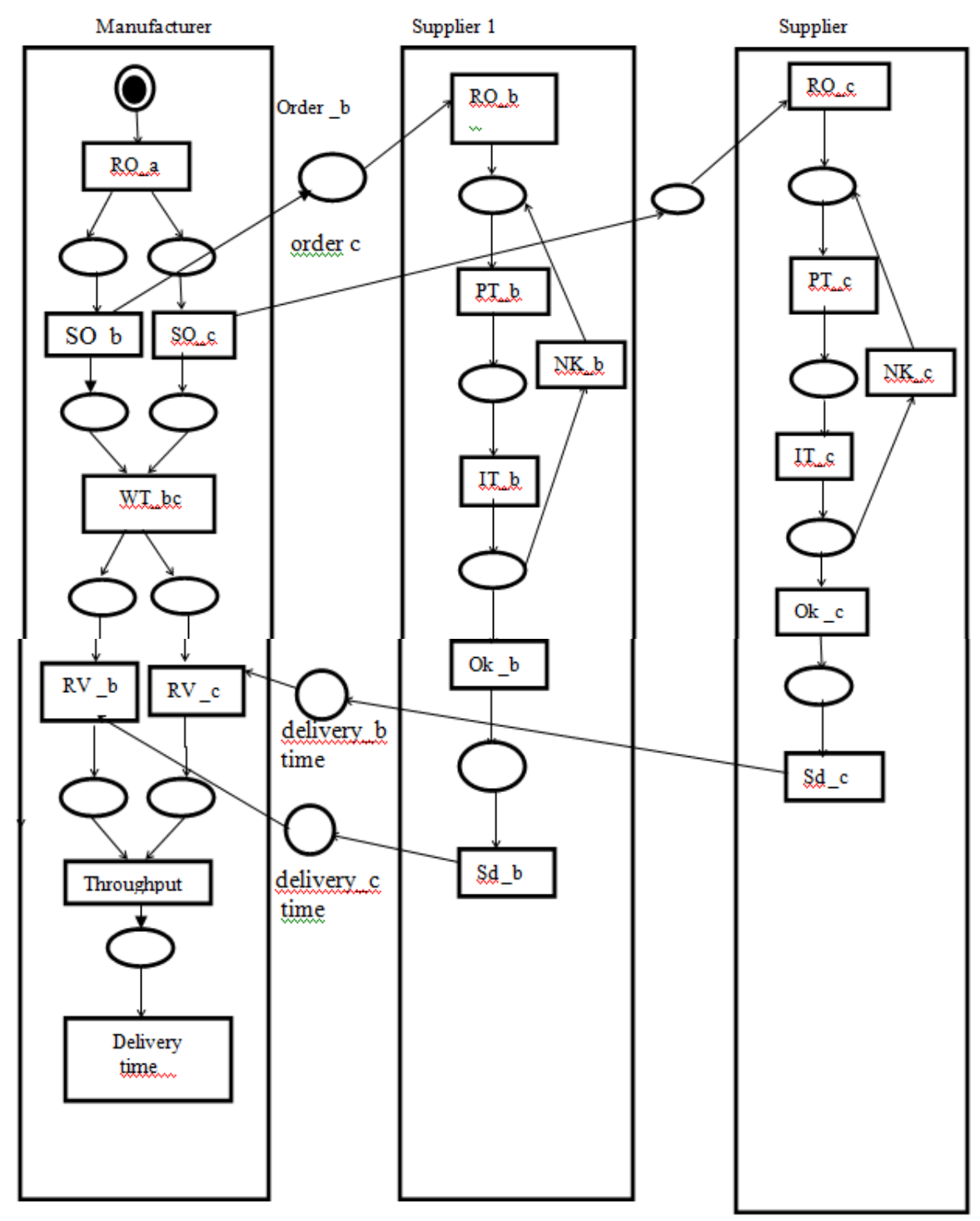

Figure 2. Work flow Net for selecting supplier in B2B 
4. Performance analysis of work flow net work flow net is used as tool for performance analysis here we use the above model of b2b e-commerce for finding out delivery time and throughput.

The performance analysis is carried on for two cases

- For generic model two-supplier model having ten suppliers for producing the product and one producer.

- For n-supplier model having ten suppliers for producing the product and one producer.

\subsection{For two supplier model having ten suppliers for producing the product and one producer.}

In this case we assume that any supplier can manufacture product $b$ and product $c$. We consider that there are 10 suppliers present to whom the producer can place the order only for two suppliers. The order is randomly distributed to the supplier. The one supplier is selected randomly from out of available 10 suppliers. The waiting time, process time, queue time, move time are generated randomly. The inspection time is calculated depending upon the accuracy which is generated randomly. If the accuracy is equal to one then the product manufactured is accurate then the inspection time is less compared to inspection time when accuracy is less than 1 . The throughput is calculated by summing of inspection time, queue time, process time and move time. The delivery time is calculated as sum of waiting time and throughput.

\subsection{For n-supplier model having ten suppliers for producing the product and one producer:}

The n-supplier model is used to have any number of suppliers. Here we restrict suppliers to ten, who are available to supply the product $b$ and product $c$ to producer. If the value of $n=2$ two suppliers are selected, if $n=3$ three suppliers are selected out of 10 suppliers. Finally using throughput and delivery time is calculated using the randomly calculated using move time, queue time, process time and inspection time which are divided by $n$.

Algorithm for performance analysis of b2b e-commerce. The b2b performance analysis for $\mathrm{n}$-supplier is given below which calculate delivery time and throughput depending on this selection of supplier is done. This was executed in MAT Lab. The selection of supplier is chosen on less throughput time and less delivery time.

1. Start.

2. Read n, number eligible suppliers.

3. Randomly select supplier from available suppliers here we consider 10 suppliers.

4. Randomly generate order for the product, where order divided by n-suppliers.

5. Randomly generate the move time, the process time, divided by $n$ - suppliers move time, the process time.

6 Randomly generate queue time and inspection time, divided by n-suppliers queue time and inspection time.

7. The inspection time is calculated depending upon the whether the product is accurately manufactured or not. 
8 . If the accuracy is equal to 1 which also randomly generated the inspection time is less, otherwise the product manufactured is considered as defective and inspection time is more.

9. Randomly generate the waiting time where the customer should wait for delivery of the product.

10. Throughput $=$ move time + process time + queue time + inspection time.

11. Delivery time $=$ waiting time + throughput.

12. Stop.

\section{Algorithm 1. Performance analysis algorithm for e-procurement in B2B}

\section{Test cases and result analysis.}

Selection of supplier is made by seeing supplier involvement chart and throughput and delivery time chart twice validation is made to select best supplier among present.

Case 1: The first test case considered the generic model having two supplier involvements in supplying the product $\mathrm{b}$ and product $\mathrm{c}$. The suppliers are randomly selected from among available suppliers. The table and graph shows the supplier involved in producing the product $\mathrm{b}$ and product $\mathrm{c}$.

The table 1 shows the suppliers involvement in two supplier performance of $b 2 b \quad e$ commerce. The supplier are randomly selected from among available suppliers here we consider 10 suppliers. The table shows in iteration 1 supplier 9 , product $\mathrm{b}$ is manufactured and supplier 10, product $\mathrm{c}$ is manufactured, iteration 2 supplier 2 manufacture product $\mathrm{b}$ and supplier 5 who manufactures product $\mathrm{c}$. In iteration 4 supplier4 is involved to manufacture product $\mathrm{b}$ and product $\mathrm{c}$ this may happen when no supplier is present this situation may happen.

\begin{tabular}{|c|l|l|l|l|l|l|l|}
\hline $\begin{array}{c}\text { Supplier } \\
\text { no }\end{array}$ & Iteration1 & Iteratio2 & $\begin{array}{l}\text { Iteration } \\
3\end{array}$ & Iteration4 & Iteration5 & Iteration6 & Iteration7 \\
\hline Supplier1 & & & 1 & & & & 2 \\
\hline Supplier2 & & 1 & & & & 1 & \\
\hline Supplier3 & & & & & 1 & & \\
\hline Supplier4 & & & & 2 & & 1 & \\
\hline Supplier5 & & 1 & & & & & \\
\hline Supplier6 & & & & & & & \\
\hline Supplier7 & & & & & & & \\
\hline Supplier8 & & & 1 & & 1 & & \\
\hline Supplier9 & 1 & & & & & & \\
\hline Supplier10 & 1 & & & & & & \\
\hline
\end{tabular}

Table 1: supplier involvement in b2b e-commerce using Petri net 
The chart shown below gives the number of times involvement of the supplier, the algorithm is run for 7 iterations they are ten suppliers available among them only two suppliers are randomly selected and sometimes same supplier is randomly selected for e.g. in iteration 7 and 4 supplier 1 and supplier 4 are selected indicating they will produce both sub product. The supplier 6 not involved in the manufacturing either of two product $\mathrm{b}$ and $\mathrm{c}$.

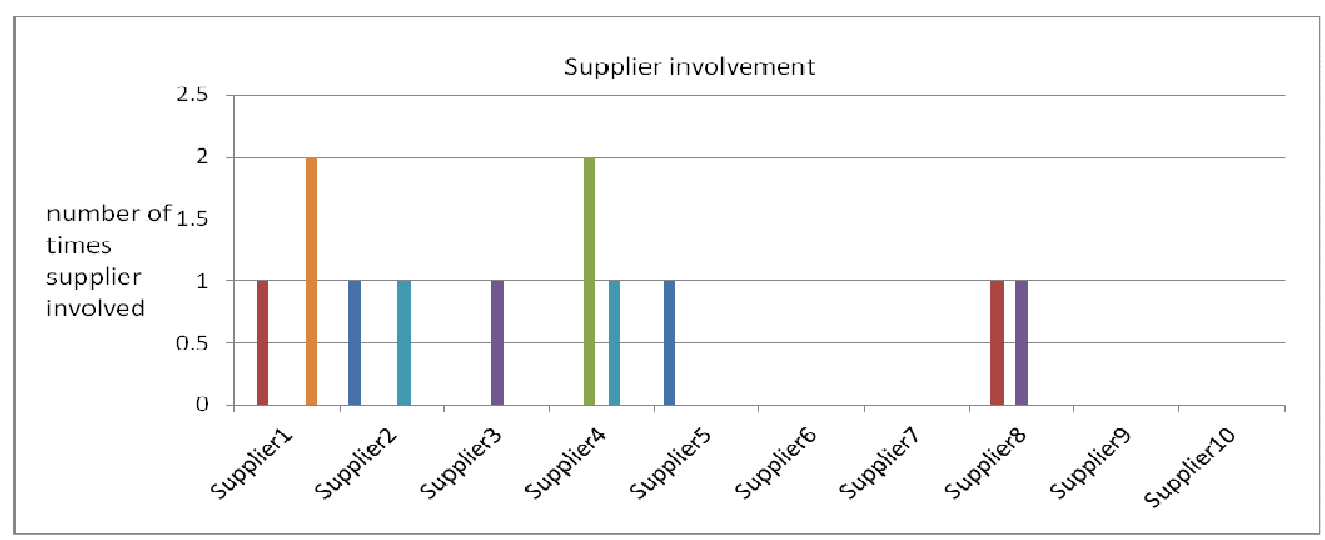

Chart 1.Supplier involvement in manufacturing sub product in generic model.

The throughput and delivery time for the manufacturing product a using two supplier is shown in the table 2.The suppliers are randomly selected from available supplier here we assume 10 suppliers are present.

Table 2. Throughput and Delivery time for Product a for two supplier

\begin{tabular}{|c|c|c|}
\hline Iteration & Throughput & Delivery time \\
\hline 1 & 91.17 & 165.43 \\
\hline 2 & 116.125 & 278.033 \\
\hline 3 & 53.65 & 146.78 \\
\hline 4 & 153.802 & 257.84 \\
\hline 5 & 132.47 & 317.64 \\
\hline 6 & 113.64 & 197.318 \\
\hline 7 & 135.9 & 243.23 \\
\hline 8 & 94.488 & 215.15 \\
\hline 9 & 62.98 & 231.902 \\
\hline 10 & 122.313 & 223.113 \\
\hline 11 & 156.3 & 255.33 \\
\hline 12 & 125.45 & 156.62 \\
\hline 13 & 95.56 & 183.72 \\
\hline 14 & 131.33 & 275.8 \\
\hline
\end{tabular}


The graph for the throughput and delivery time of the product is given below in the graph shown below. The graph shows the that fifth iteration the delivery time is more and throughput is more in iteration 4 , we finally select iteration 3 in the chart 2 and check for supplier in supplier involvement chart 1 which have the supplier1 and supplier 8 so it best to choose them as the throughput and delivery time is approximately less compared to others.

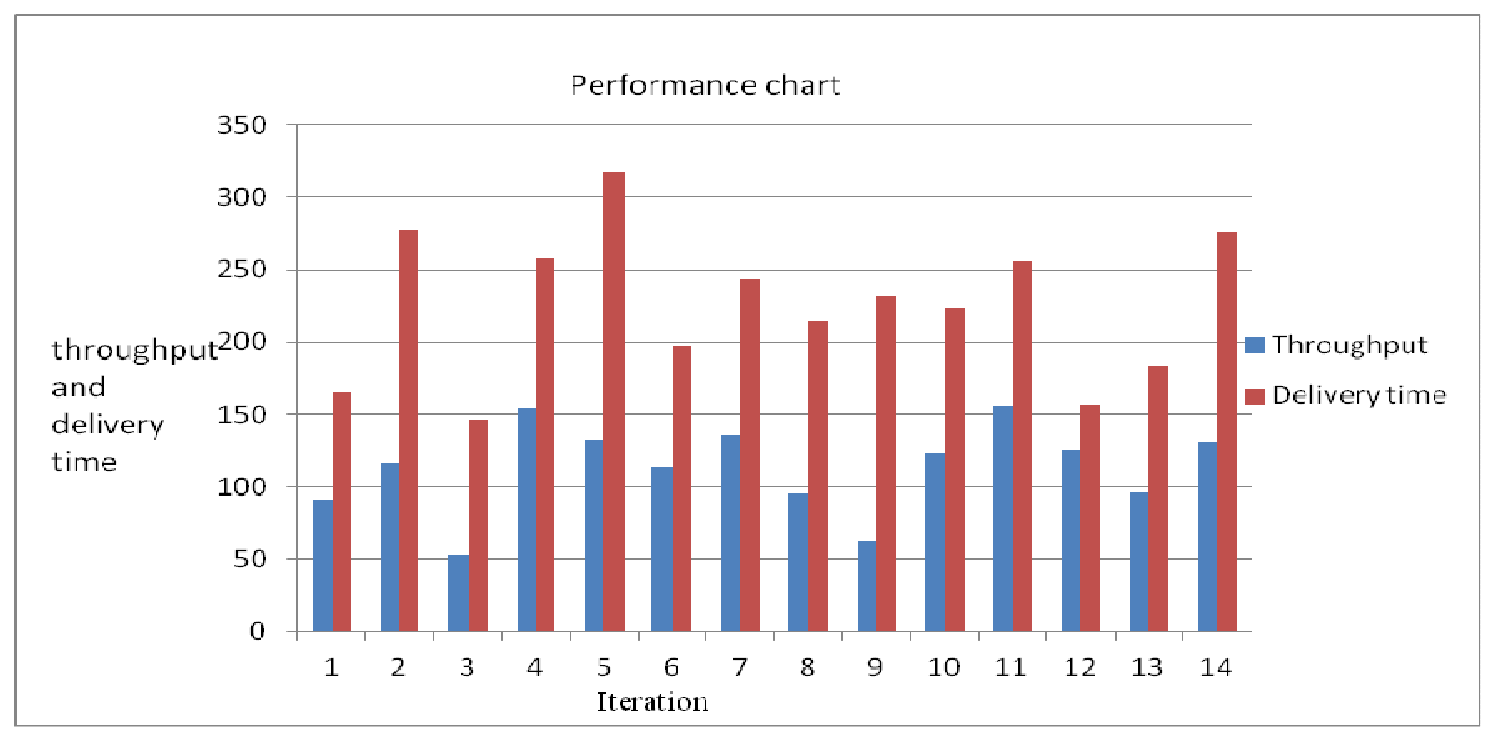

Chart 2. Throughput and delivery time for product a in generic model.

Case 2: in this we consider $\mathrm{n}$-supplier involved in manufacturing sub product $\mathrm{b}$ and sub product c suppliers are selected randomly from 10 suppliers. The $n$-suppliers involvement chart consist of involvement of different suppliers randomly selected for manufacturing product $\mathrm{b}$ and product $\mathrm{c}$. The table 2 shows suppliers selected randomly from among 10 suppliers. Table 2 has 7 iteration and 10 suppliers, iteration 1 means only one supplier is considered, in iteration 2 two suppliers are selected randomly from available 10 suppliers, same is carried on for other iteration.

Table 3. Supplier involvement in manufacturing sub product in $\mathrm{n}$-supplier model

\begin{tabular}{|l|l|l|l|l|l|l|l|}
\hline $\begin{array}{l}\text { Supplier } \\
\text { number }\end{array}$ & $\begin{array}{l}\text { Iteration } \\
1\end{array}$ & $\begin{array}{l}\text { Iteration } \\
2\end{array}$ & $\begin{array}{l}\text { Iteration } \\
3\end{array}$ & $\begin{array}{l}\text { Iteration } \\
4\end{array}$ & $\begin{array}{l}\text { Iteration } \\
5\end{array}$ & $\begin{array}{l}\text { Iteration } \\
6\end{array}$ & $\begin{array}{l}\text { Iteration } \\
7\end{array}$ \\
\hline Supplier1 & & & 1 & & 2 & 1 & 3 \\
\hline Supplier2 & & & & & & & \\
\hline Supplier3 & & & & 1 & & 1 & 1 \\
\hline Supplier4 & & & & & & 1 & 1 \\
\hline Supplier5 & & & 1 & & & 1 & \\
\hline Supplier6 & & & & 1 & 2 & & 1 \\
\hline Supplier7 & & 1 & & 1 & & & \\
\hline Supplier8 & & & & 1 & 1 & & \\
\hline Supplier9 & 1 & & & & & 2 & 1 \\
\hline Supplier1 & & 1 & 1 & & & & \\
\hline
\end{tabular}


The chart for the all the iteration is given below which shows supplier 1 is called 3 times in iteration 7. Supplier 6 and supplier 9 are called twice iteration 5 and iteration 6 respectively.

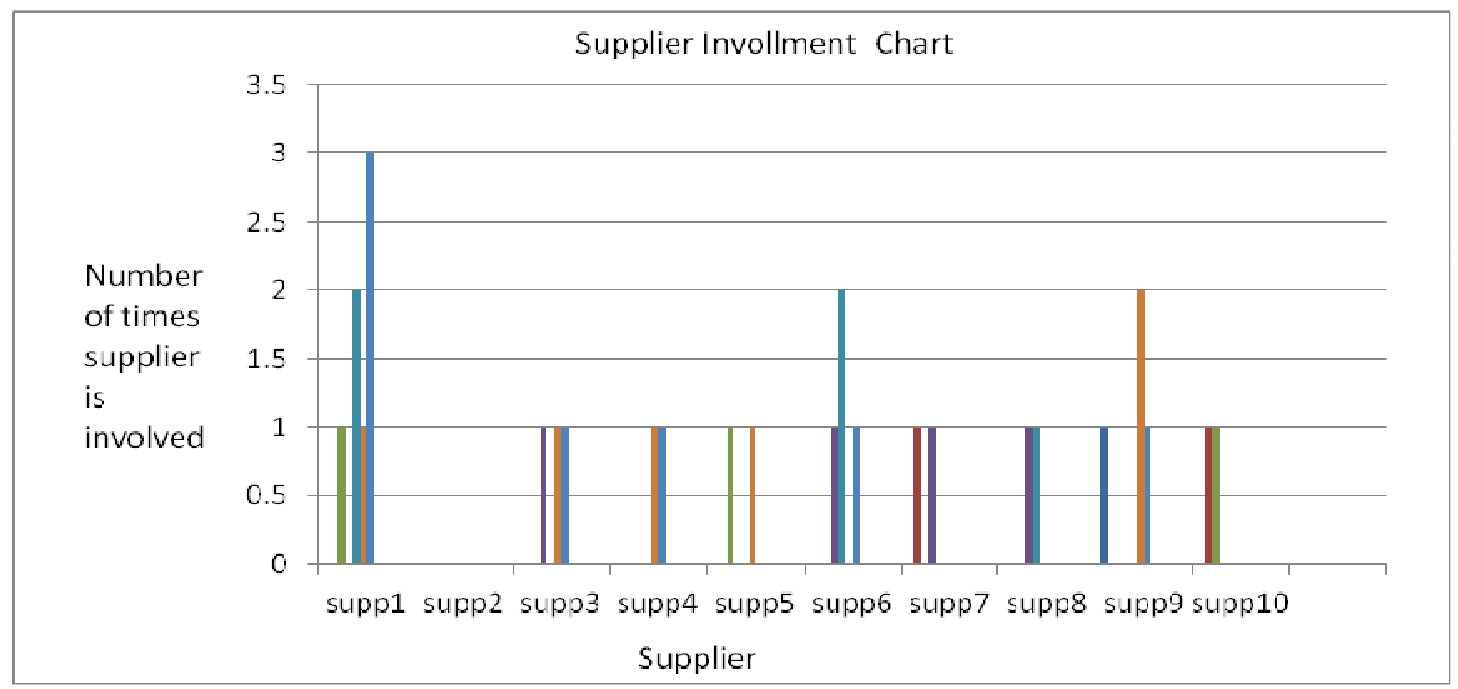

Chart 3. Supplier involvement chart in n-supplier for manufacturing sub product

The throughput and delivery time for delivery time the completely manufactured product a using n-supplier is shown in the table using randomly selected suppliers here we consider 10 suppliers.

Table 4. Throughput and delivery time for manufacturing product a in n-supplier model.

\begin{tabular}{|l|l|l|}
\hline Iteration & Throughput & Delivery time \\
\hline 1 & 430.474 & 456.74 \\
\hline 2 & 111.64 & 217.36 \\
\hline 3 & 118.013 & 194.706 \\
\hline 4 & 111.215 & 188.84 \\
\hline 5 & 84.36 & 172.56 \\
\hline 6 & 84.57 & 190.82 \\
\hline 7 & 94.03 & 199.69 \\
\hline 8 & 93.137 & 154.76 \\
\hline 9 & 113.43 & 209.25 \\
\hline 10 & 98.36 & 193.36 \\
\hline 11 & 107.27 & 210.56 \\
\hline 12 & 129.592 & 224.017 \\
\hline
\end{tabular}

The graph for the throughput and delivery time of the product is given below in the graph shown below. The graph shows that in iteration 1 only one supplier is considered in this case the selected supplier9 is selected for producing both product $\mathrm{b}$ and product $\mathrm{c}$ as a result the delivery time is 
more and least is in iteration 8 having eight suppliers who are supplier2, supplier3, supplier4, supplier5 is given order twice and supplier10 is given order twice so it best to choose this combination of suppliers as the throughput and delivery time is less.

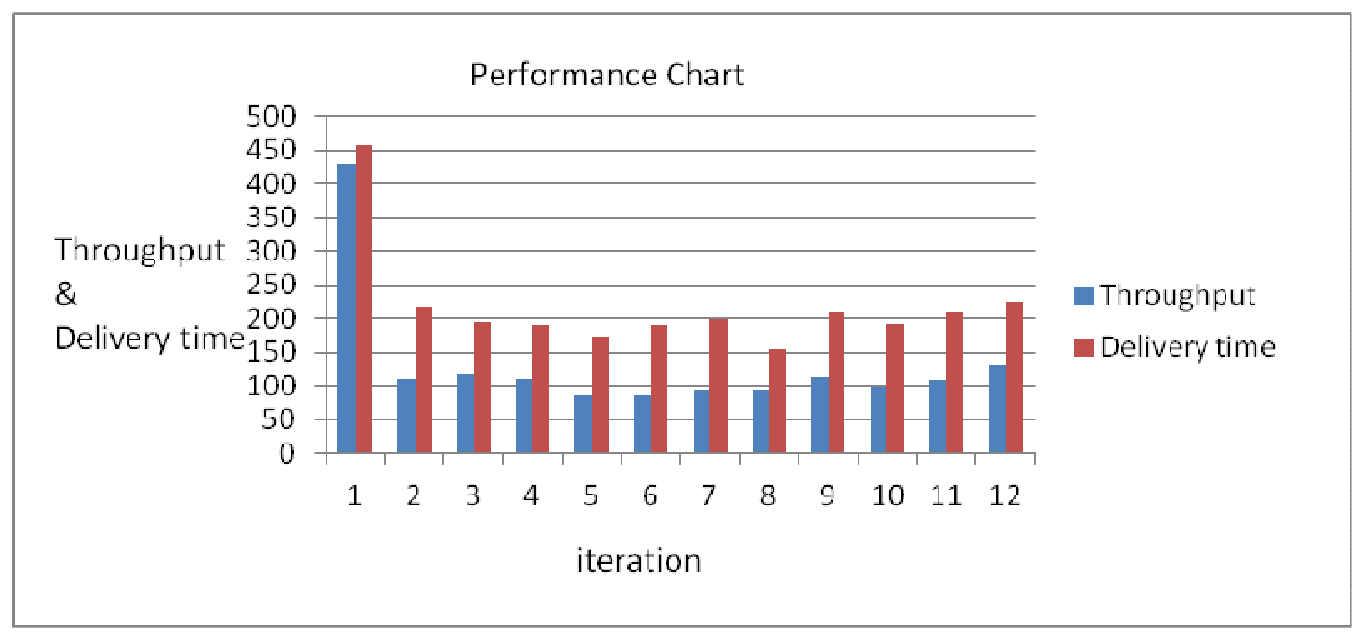

Chart 4 Throughput and delivery time for manufacturing product a in n-supplier model

\section{Conclusion}

Speed and distribution in every aspect of most business and organization undertaking characterize the new millennium. Organizations are challenged to bring ideas and concepts to products and services in an ever increasing pace. Companies distributed by space, time and capabilities come together to deliver products and solutions for which there is any need in the global marketplace. The selection of the supplier in this dynamic b2b is most important, which is represented in the form of work flow net. Here we have selecting the supplier depending on their involvement in the manufacturing of the sub product which is characteristic of the supplier and second we check the traditional parameter like throughput and delivery time by which we get best suppliers from the available pool of the suppliers. Twice validation is done for extracting best supplier.

\section{References}

1. Barrat, M. . Understanding the meaning of collaboration in the supply chain.Supply Chain Management: An International Journal, 9 (1)(2005), 30-42.

2. Chiu, D.et.al., Developing e-negotiation support with a meta-modeling approach in a web services environment. An international journal of Decision Support Systems 40(1) (2005) 51-69

3. Disney, S.M., et.al, Assessing the impact of e-business on supply chain dynamics. International Journal of Production Economics, 89 (2) (2004), 109-118

4. Gayialis, S., \&Tatsiopoulos I. Design of an IT-driven decision support system for vehicle routing and scheduling.European Journal of Operational Research, 152 (2)(2004), 382-398.

5. Henderson, P.,.et.al, Comparison of some negotiation algorithms using a tournament-based approach. In: Agent Technologies, Infrastructure, Tools and Applications for E-Services. Volume 2592 of Lecture Notes in Artificial Intelligence. Springer (2003) 137-150

6. McIvor, R., Humphreys, P., \&McAleer, W. The implications of the trend towards partnership sourcing on buyer-supplier relations. The Journal of General Management, 23 (1)(1997), 1-5.

7. Stank, T.P., Crum, M., \&Arango, M. Benefits of inter-firm co-ordination in food industry supply chains. Journal of Business Logistics, 20 (2)(1999), 21-41.

8. Weigand, H., Heuvel,W. Cross-organizational workflow integration using contracts. International journal of Decision Support Systems 33(3)(2002) 247-265. 
9. Venkatraman, N., \& Henderson, J. C.Real strategies for virtual organizing. Sloan Management 40(1)(1998), 33-48.

10. Alderete Maria Veronica, E-commerce between a large firm and a SME supplier: a screening model,journal of computing,1(1), (2009) .

11. S.HosseinCheraghiet.al , Critical success factors for supplier selection: An update, Journal of Applied Buisness Research,20(2), (2010).

12. P.Priya et.al, E-procuremetn system with embedded supplier selection DSS for an Automobile Manufacturing Industry, International Journal of Database Management systems, 4(2),2012.

13. Lu Shan, Evaluation on suppliers selection in the context of E-commerce based on Trapezoidal Fuzzy order weighted Average operator, Journal of software,7(20),2012,pp 2372-2378.

14. William Kuechler, Supporting optimization business-to-business e-commerce relationships, Decision Support Systems,31,2001,pp 363-377.

15. Massima Mecella et.al Modeling E-service Orchestrations through Petri net, TES 2002,LNCS 2444,2002,pp.38-47.

16. W.M.P. Van Der Aalst ,Process oriented Architectures for electronic commerce and inter organizational workflow ,International Journal of Information system , (1999),pp 4378-4398,

17. Luitzen et.al, A review of methods supporting supplier selection,

\section{Authors}

Dr.K.N.Subramanya, vice principal of R.V.College of engineering expert in SCM, E-commerce, b2b.Published paper in reputed journals on SCM, traditional and Cloud supply chain, B2B market design.

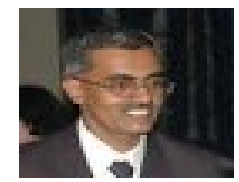

Mrs. Samara Mubeen Assistant professor in department of Information and Science of Jnnce college. I am research scholar, pursuing research in B2B technology, strategy Involved in the b2b market, performance analysis in B2B market using analytical Tool.

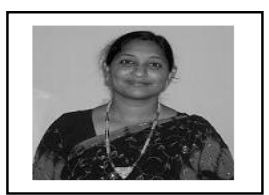

